\title{
Introduction to the Theme for 2015: Integration
}

\author{
Peter G. M. de Jong ${ }^{1}$
}

Published online: 4 August 2015

(C) International Association of Medical Science Educators 2015

Starting with the current issue, Medical Science Educator is introducing a new feature of the journal: "journal sections" on a specific topic. These thematic sections are the successor of the special issues that were published annually over the past several years. I know that many of our readers highly appreciated and enjoyed these supplements. The content for the thematic sections is solicited by a special call for manuscripts, and for 2015, the accepted articles will be published in issues 25(3) and 25(4).

The theme that has been selected for 2015 is Integration. The concept of integration is important in medical education in general. Think of integration of basic science knowledge in clinical teaching, or integration of clinical cases in the basic science curriculum, or even integration of several disciplines or pedagogies into one teaching unit. Medical Science Educator wants to explore the effects and outcomes of integration by learning what institutions are doing in this area.
The journal received almost 40 manuscripts for this section, and in this issue, the first three articles are being published. Harris and colleagues describe the use of a portfolio system to enhance integration of fields like anatomy, humanities, and physiology through better organization of materials and timely feedback from teachers to students. Johnson describes a game to integrate statistical content with systems-based content in the undergraduate medical curriculum. And finally, Loftus comments on the complexity of the concept of integration by considering integration at the curriculum as well as the student level.

I hope you will enjoy these first three articles to be published in the journal section on Integration.

Peter G.M. de Jong, PhD

Editor-in-Chief

Peter G. M. de Jong

P.G.M.de_Jong@lumc.nl

1 Leiden University Medical Center, Leiden, The Netherlands 